Article

\title{
Are Microplastics Impairing Marine Fish Larviculture?-Preliminary Results with Argyrosomus regius
}

\author{
Diana Campos ${ }^{1}$, Andreia C. M. Rodrigues ${ }^{1, *(\mathbb{D})}$, Rui J. M. Rocha ${ }^{1}{ }^{\oplus}$, Roberto Martins ${ }^{1}{ }^{1}$, Ana Candeias-Mendes ${ }^{2}$, \\ Sara Castanho ${ }^{2}\left(\mathbb{D}\right.$, Florbela Soares ${ }^{2}$, Pedro Pousão-Ferreira ${ }^{2}$, Amadeu M. V. M. Soares ${ }^{1}\left(\mathbb{D}\right.$, Carlos Gravato $^{3}(\mathbb{D}$ and \\ Ana L. Patrício Silva ${ }^{1}$
}

check for updates

Citation: Campos, D.; Rodrigues, A.C.M.; Rocha, R.J.M.; Martins, R.; Candeias-Mendes, A.; Castanho, S.; Soares, F.; Pousão-Ferreira, P.; Soares, A.M.V.M.; Gravato, C.; et al. Are Microplastics Impairing Marine Fish Larviculture?-Preliminary Results with Argyrosomus regius. Water 2021, 13, 104. https://doi.org/10.3390/ w13010104

Received: 30 November 2020 Accepted: 28 December 2020 Published: 5 January 2021

Publisher's Note: MDPI stays neutral with regard to jurisdictional clai$\mathrm{ms}$ in published maps and institutional affiliations.

Copyright: (C) 2021 by the authors. Licensee MDPI, Basel, Switzerland. This article is an open access article distributed under the terms and conditions of the Creative Commons Attribution (CC BY) license (https:// creativecommons.org/licenses/by/ $4.0 /)$.
1 CESAM-Centre for Environmental and Marine Studies, Department of Biology, University of Aveiro, 3810-193 Aveiro, Portugal; diana.campos@ua.pt (D.C.); ruimirandarocha@ua.pt (R.J.M.R.); roberto@ua.pt (R.M.); asoares@ua.pt (A.M.V.M.S.); ana.luisa.silva@ua.pt (A.L.P.S.)

2 IPMA-Portuguese Institute for the Ocean and Atmosphere, EPPO-Aquaculture Research Station, Av. Parque Natural da Ria Formosa s/n, 8700-194 Olhão, Portugal; ana.mendes@ipma.pt (A.C.-M.); scastanho@ipma.pt (S.C.); fsoares@ipma.pt (F.S.); pedro.pousao@ipma.pt (P.P.-F.)

3 Faculty of Sciences and CESAM, University of Lisbon, Campos Grande, 1749-016 Lisbon, Portugal; cagravato@fc.ul.pt

* Correspondence: rodrigues.a@ua.pt

Abstract: The presence of small-sized $(<300 \mu \mathrm{m})$ microplastics (MPs) in aquaculture facilities may threaten finfish hatchery, as their (in)voluntary ingestion by fish larvae may compromise nutritional requirements during early ontogeny, and consequently larval health and performance. Thus, we addressed the short-term effects $(7 \mathrm{~h})$ of polyethylene microplastics $(0.1,1.0,10 \mathrm{mg} / \mathrm{L}, \mathrm{PE}-\mathrm{MPs})$ in meagre larvae Argyrosomus regius (15 dph) in the presence/absence of food. Larval feeding behavior, oxidative stress status, neurotoxicity, and metabolic requirements were evaluated. Results showed that meagre larvae ingested PE-MPs regardless of their concentration, decreasing in the presence of food (Artemia metanauplii). The presence of PE-MPs compromised larval feeding activity at the highest concentration. Under starvation, exposed larvae activated the antioxidant defenses by increasing the total glutathione levels and inhibiting catalase activity, which seemed efficient to prevent oxidative damage. Such larvae also presented increased energy consumption potentially related to oxidative damage prevention and decreased neurotransmission. Biochemical responses of fed larvae showed a similar trend, except for LPO, which remained unaffected, except at $0.1 \mathrm{mg} / \mathrm{PE}-\mathrm{MPs} / \mathrm{L}$. Our results suggest that small-sized MPs in finfish hatcheries may compromise larvae nutritional requirements, but at considerably higher levels than those reported in marine environments. Nevertheless, cumulative adverse effects due to lower MPs concentrations may occur.

Keywords: plastic pollution; polyethylene; oxidative stress status; neurotoxicity; farmed fish species

\section{Introduction}

Aquaculture represents an essential food source for the world's human population, contributing significantly to welfare and food security. For this reason, aquaculture is being prioritized by the 2030 Agenda, and it is expected to reach 109 million tonnes by 2030 [1]. The success and sustainability of aquaculture at a global scale rely on hatcheries, where breeding, egg fertilization, incubation, hatching, and rearing of organisms, particularly finfish, through early-life stages is carried out artificially, in controlled and optimized conditions. However, fish larvae are very vulnerable during their first stages of development and undergo a severe bottleneck due to nutritional restriction, affecting their survival, and consequently, the overall fish production [2]. Newly hatched fish survive on a limited yolk supply and must encounter and successfully capture nutritionally adequate feed (e.g., zooplankton) before their energy resources become depleted [3]. Thus, adequate feeding is of pivotal importance to improve digestive capacities and ensure proper nutrition during early development to guarantee survival, growth, and health of fish larvae [4]. 
An emergent threat to this process is the presence of microplastics (MPs) with $<300 \mu \mathrm{m}$ in size, as they can easily resemble food items (as microalgae, zooplankton cyst/eggs) and be actively or passively captured by many planktivores, such as fish larvae. The ingestion of MPs by several fish species at larval stages have been reported in previous studies, with consequent obstruction of the gastrointestinal tract, decreased feeding activity due to a false sensation of satiation, compromised fish reproduction, and decreased larval growth $[5,6]$. Exposure of fish to small-sized MPs also seems to affect larval swimming capacity, induce inflammatory and metabolic responses, and affect other tissues through translocation processes [6].

The presence of MPs in aquaculture facilities is a reality, as the majority of the aquaculture systems and infrastructures (e.g., tanks and fish cages, pumps, nets, aerial traps and pots, buoyant material, among others) are based on plastic materials that are likely to degrade due to physico-chemical and biological processes [7]. In addition, hatcheries mostly rely on open systems and require water from natural environments. The presence and levels of MPs in both freshwater and marine waters is widely recognized: (1) Ma et al. [8] observed a maximal abundance of 87.5 particles/L found in Pearl River estuary of Guangzhou, China; (2) Chen et al. [9] observed the presence of MPs in mariculture on Xiangshan Bay, China, with concentrations ranging from 4.6 to 20.1 items $/ \mathrm{m}^{3}$ in seawater and $5570 \pm 296 \mathrm{MPs} / \mathrm{kg}$ in sediments. However, these levels might be underestimated, as the majority of environmental surveys do not account for microplastics smaller than $300 \mu \mathrm{m}$ [10]. It is predicted that 11.6-21.1 million tonnes of MPs ranging between 32-651 $\mu \mathrm{m}$ in size are suspended in the top of surface water (above $200 \mathrm{~m}$ ) of the Atlantic Ocean [11]. Moreover, atmospheric deposition and commercial fish feeding products also constitute MPs sources to aquacultures [12,13]. Thus, an integrated understanding of how MPs may interfere with the food acquisition and processing by farmed fish larvae is necessary to apply potential mitigation measures to fulfil the nutritional requirements.

Meagre Argyrosomus regius has been recently identified as a promising species with high potential for the diversification of finfish aquaculture in the Mediterranean $[4,14]$. Using this organism as test species, this research aimed at understanding to which extent the presence of MPs affects the feeding behavior, oxidative stress status, neurotoxicity, and metabolic requirements in their larval stage, considering a real aquaculture scenario often neglected (i.e., presence/absence of food for a short-term period). For this purpose, meagre fish larvae with 15 days post-hatching (dph) were exposed to increased concentrations of polyethylene microplastics (PE-MPs) for $4 \mathrm{~h}$, followed by $3 \mathrm{~h}$ exposure in the presence or absence of alive prey. The working hypotheses are as follows: (i) meagre larvae ingest PE-MPs; (ii) health status and feeding behavior of meagre fish larvae are affected by PEMPs ingestion; and (iii) feed restrictions (e.g., during dark period when usually uneaten feed-live preys - are discarded) may exacerbate the potential physiological/biochemical effects of PE-MPs.

\section{Materials and Methods}

\subsection{Organisms Culture Conditions}

Fish larvae of Argyrosomus regius used in the assay were provided from EPPO-IPMA (Estação Piloto de Piscicultura de Olhão-Instituto Português do Mar e da Atmosfera, Portugal).

Meagre eggs were obtained from F1 broodstock (126 g viable eggs) on 21 April 2019. After the incubation period, hatched larvae (hatching rate 53.4\%) were distributed into $1500 \mathrm{~L}$ cylindroconical tanks at a density 44 larvae/L. Since the time of mouth opening ( $3 \mathrm{dph}$ ) to $11 \mathrm{dph}$, meagre larvae were able to feed on rotifers (3-7 dph: 4 times/day, 8-10 dph: 3 times/day; 11 dph: 1 time/day). Artemia (EG $24 \mathrm{~h}$ metanauplii enriched with RedPepper, 3-4 times/day until weaning-1 time/day) and caviar (100-200 $\mu \mathrm{m})$ were introduced after 8 and $11 \mathrm{dph}$, respectively, and ad-libitum. The oxygen level was $5.0 \pm 0.15 \mathrm{mg} / \mathrm{L}$, and the temperature was $20.7 \pm 1.38^{\circ} \mathrm{C}$. Larvae used for testing had $15 \mathrm{dph}$, with a size-average of $4 \mathrm{~mm}$. 


\subsection{Microplastic Particles Used in the Assay and Spiking}

Low-density polyethylene was chosen, given its frequent detection in aquaculture [15]. Polyethylene microparticles (size: $125 \mu \mathrm{m}$, density $960 \mathrm{~kg} / \mathrm{m}^{3}$, shape: irregular/powder, CAS Number 9002-88-4) were purchased in Sigma-Aldrich, UK. Commercial microplastics were sieved in a vibratory sieve shaking, and particles with a size between $63-125 \mu \mathrm{m}$ were selected and used in the bioassay, like the average size of food items provided during the rearing procedure. Three different stock solutions $(15,150$, and $1500 \mathrm{mg} / \mathrm{L})$ were prepared in filtered $\left(0.45 \mu \mathrm{m}\right.$ pore size) artificial seawater (practical salinity 35 ; Tropic Marin ${ }^{\circledR}$ Pro Reef salt mixed with reverse osmosis water). Microplastics were allowed to age for one week. For this purpose, stock solutions were agitated continuously for one week at $50 \mathrm{rpm}$ (orbital shaker) at room temperature, in the dark. Final concentrations were obtained by adding $1 \mathrm{~mL}$ of the respective solution to each glass containing $149 \mathrm{~mL}$ of seawater (final concentrations: $0.1,1.0,10 \mathrm{mg} / \mathrm{L}$ ). In control conditions ( $0 \mathrm{mg} / \mathrm{L} \mathrm{MPs})$, a volume of $1 \mathrm{~mL}$ of artificial seawater (also left to shake in the same conditions that MPs stock solution) was added to each glass vial of such treatment. Such high PE-MPs concentrations were chosen to stimulate larvae to initiate feeding during the relatively short experimental period and infer potential thresholds on feeding behavior and physiological/biochemical endpoints (as further explained in the next section).

\subsection{Experimental Setup}

Argyrosomus regius larvae ( $15 \mathrm{dph}$ ) were exposed for $4 \mathrm{~h}$ to the three PE-MP concentrations $(0.1,1$, and $10 \mathrm{mg} / \mathrm{L})$ and a control treatment $(0 \mathrm{mg}$ PE-MPs/L). This period was followed by an additional $3 \mathrm{~h}$ exposure, where half of the treatments were fed with live prey (5 Artemia metanauplii/mL), and another half remained without food supply. Thus, a total of eight treatments were prepared according to Figure 1.

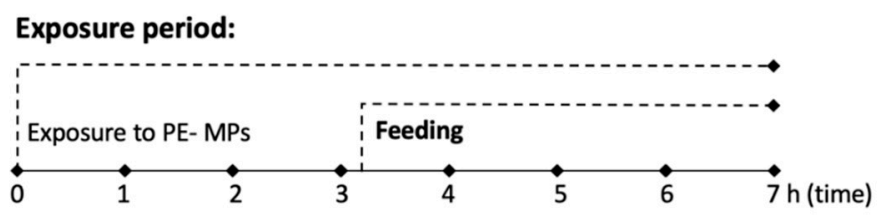

Treatments:

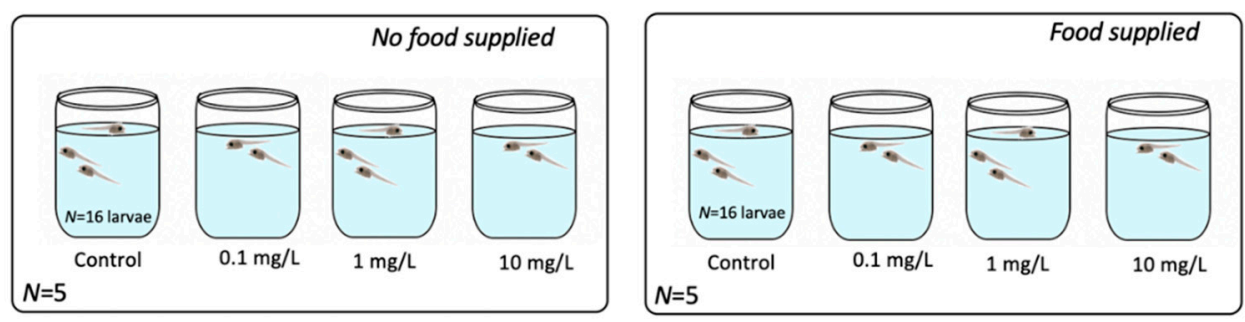

Endpoints:

\begin{tabular}{|c|c|c|}
\hline$\checkmark$ Ingestion of PE-MPs & $\checkmark$ Gut content & \\
\hline$\checkmark$ Neurotransmission & $\checkmark$ Oxidative stress \& damage & $\checkmark$ Aerobic energy production \\
\hline
\end{tabular}

Figure 1. Schematic representation of the experimental setup and target endpoints.

Briefly, each treatment consisted of five glass vials, each containing $150 \mathrm{~mL}$ of test medium and 16 meagre larvae (although corresponding to a density of 107 larvae/L, it does not compromise meagre larvae survival as in Roo et al. [16]). The experiment was conducted at controlled temperature of $19 \pm 1{ }^{\circ} \mathrm{C}$ with no aeration. Water parameters were monitored at the beginning and the end of the experiment. After exposure, two pools of three fish larvae were anaesthetized with 1\% 2-phenoxyethanol, gently rinsed with Milli-Q ultra-pure water. Then one pool was preserved in $70 \%$ ethanol to assess the ingestion of PE-MPs, and the other pool was fixed with $4 \%$ formaldehyde to assess gut content. The 
remaining fish larvae were sensed with Milli-Q ultra-pure water, gently dried with filter paper, placed into $2 \mathrm{~mL}$ Eppendorf tubes, and deep-frozen in liquid nitrogen to assess biochemical responses.

\subsection{Extraction and Quantification of Microplastics}

Before extraction and quantification of MPs, all larvae were (once more) gently rinsed and observed under the stereomicroscope to verify the absence of PE-MPs adhered to their skin. The PE-MP extraction followed the optimized protocol developed by Silva et al. [17], whereas the quantification method followed Prata et al. [18]. Briefly, to assess the presence of PE-MPs inside organisms, larvae were placed in glass flasks, covered with aluminum foil, and dried at $50{ }^{\circ} \mathrm{C}$ for $24 \mathrm{~h}$. Afterwards, $3 \mathrm{~mL}$ of nitric acid $\left(\mathrm{HNO}_{3}, 65 \%\right)$ was added to each replicate and incubated at $60^{\circ} \mathrm{C}$ for three hours. After this period, samples were allowed to cool down to room temperature (RT), and $2.6 \mathrm{~mL}$ of hydrogen peroxide $\left(\mathrm{H}_{2} \mathrm{O}_{2}, 35 \%\right)$ were added. Samples were incubated at RT overnight. Then, samples were diluted with $50 \mathrm{~mL}$ of Milli-Q ultra-pure water and immediately vacuumed filtered onto black polycarbonate filters (PCTE, $0.2 \mu \mathrm{m}$ pore size, $42 \mathrm{~mm} \varnothing$, ref. 7063-4702, Cytiva WhatmanTM, Fisher Scientific, Portugal) to retain PE-MPs. Microplastics were stained with $1 \mathrm{~mL}$ of Nile red (Sigma Aldrich, St. Louis, MO, USA; stock solution: $0.01 \mathrm{mg} / \mathrm{mL}$ ethanol absolute) for $5 \mathrm{~min}$ protected from the light [18]. After that, filters were washed with ultrapure water to remove the excess dye and stored in glass Petri-dishes. After drying, polycarbonate filters of each sample were photographed (Canon 550D, EF-S 18-55 mm, Oita, Japan) under a blue light (450 nm, SPEX Forensics, USA) in a dark room using an orange filter (Standard ProMaster $\left.{ }^{\circledR}\right)$, and the number of microplastics was counted.

Several measures were taken to ensure quality criteria and quality control on microplastics analysis. Glassware (thoroughly acid-washed and rinsed with Milli-Q ultrapure water) was preferential for testing and analysis; samples were prepared for digestion under a clean laminar chamber and covered with aluminum foil to avoid airborne contamination. During extraction and quantification procedures, blanks (1 every 5 samples) were prepared to address possible cross-contamination between samples.

\subsection{Gut Content Analysis}

To evaluate the gut content, larvae of each treatment (previously kept in $4 \%$ formaldehyde) were transferred to ethanol (95\%) for $2 \mathrm{~h}$, and after that, moved to potassium hydroxide (1\%) for 1 day. Then, the number of preys in fish larvae gut was quantified using a binocular microscope, after opening the fish gut with a micro scissor and extracting the content with a dissecting needle [19]. The feeding activity was expressed as the number of ingested preys per larvae.

\subsection{Oxidative Stress, Aerobic Energy Production, and Neurotoxicity}

The biochemical responses were determined following the previously optimized protocols to microplates [20-23]. Briefly, each sample was homogenized in $1000 \mathrm{~mL}$ of ultra-pure water and on ice by sonication (30 s at a pulse mode of $60 \%, 250$ Sonifier, Branson Ultrasonics). Further, three aliquots of 300, 150, and $50 \mu \mathrm{L}$ for ETS-electron transport system, LPO—lipid peroxidation, and protein quantification, respectively, were set aside. To the remaining volume $(500 \mu \mathrm{L}), 0.2 \mathrm{M} \mathrm{K}$-phosphate buffer, $\mathrm{pH}=7.4$, (1:1) was added, and samples were centrifuged at $10,000 \times g$ at $4{ }^{\circ} \mathrm{C}$ for $20 \mathrm{~min}$. Posteriorly the resultant post-mitochondrial supernatant (PMS) was divided into aliquots for CAT—catalase, GSTglutathione-S-transferase, and ChE-cholinesterase activities determination, and $\mathrm{tGSH}$ total glutathione and protein levels quantification.

To evaluate oxidative damage, lipid peroxidation was measured using Thiobarbituric acid reactive substances (TBARS) assay [24,25]. The absorbance was read at $535 \mathrm{~nm}$. Using a molar extinction coefficient $(\epsilon)=1.56 \times 105 \mathrm{M}^{-1} \mathrm{~cm}^{-1}$, the results were expressed as nmol TBARS/mg of protein. Catalase activity was measured in $20 \mu \mathrm{L}$ of PMS and determined, according to Clairborne [26]. The consumption of the hydrogen peroxide 
$\left(\mathrm{H}_{2} \mathrm{O}_{2}\right)$ was read at $240 \mathrm{~nm}$ for $2 \mathrm{~min}$, and the results were presented as $\mu \mathrm{mol} / \mathrm{min} / \mathrm{mg}$ of protein, using a $\epsilon=40 \mathrm{M}^{-1} \mathrm{~cm}^{-1}$. The activity of detoxification enzyme GS $\mathrm{T}$ was determined (50 $\mu \mathrm{L}$ of PMS), according to Habig et al. [27], by measuring the formation of glutathione dinitrobenzene $(340 \mathrm{~nm}$ ) for $3 \mathrm{~min}$. Results were expressed as $\mathrm{nmol} / \mathrm{min} / \mathrm{mg}$ of protein using a $\epsilon=9.6 \times 103 \mathrm{M}^{-1} \mathrm{~cm}^{-1}$. Effects on neurotransmission were evaluated by measuring the ChE activity, following the method described by Ellman et al. [28], Guilhermino et al. [29], and Domingues and Gravato [30]. Using acetylthiocholine as substrate and $50 \mu \mathrm{L}$ of PMS, the absorbance was read $412 \mathrm{~nm}$ for $5 \mathrm{~min}$, and the results were expressed as $\mathrm{nmol} / \mathrm{min} / \mathrm{mg}$ of protein using a $\epsilon=13.6 \times 103 \mathrm{M}^{-1} \mathrm{~cm}^{-1}$. Total glutathione levels were calculated in $50 \mu \mathrm{L}$ of PMS, according to Baker et al. [31]. The absorbance was read at $412 \mathrm{~nm}$ for 3 min following the recycling reaction of reduced glutathione in excess of glutathione reductase. The results were expressed as $\mu \mathrm{M}$ per $\mathrm{mg}$ of protein, using a standard curve with L-GSH as a standard as previously performed by Campos et al. and Rodrigues et al. [32,33]. Effects on aerobic energy production were evaluated determining the ETS activity according to De Coen and Janssen [34] with some adaptations [23].

Protein levels of each sample were determined following Bradford's method, and the absorbance was read at $592 \mathrm{~nm}$. Bovine serum albumin was used as the standard for quantification [35]. The protein of PMS was used to calculate CAT, GST, ChE activities, and tGSH levels, while total protein was used to calculate ETS activity and LPO.

\subsection{Statistical Analysis}

Significant effects on the feeding activity of $A$. regius larvae after exposure were evaluated through one-way analyses of variance (ANOVA). Polyethylene microplastics ingestion and biochemical responses were evaluated by two-way ANOVA being PE-MPs concentration one factor and presence/absence of food another factor. The control condition $(0 \mathrm{mg} / \mathrm{L}$ of PE-MP) was excluded in the analysis of microplastics ingestion since no ingestion is expected/occurs in the absence of MPs. The normality of all variables was assessed on residues using the Shapiro-Wilk test, while Levene's test verified the homoscedasticity of data $(p>0.05)$. Dunnett's test was used to determine significant differences from respective controls $(p<0.05)$. All the statistical analysis and graphical representation of the results were performed using GraphPad Prism 8 (GraphPad Software, San Diego, CA, USA).

\section{Results and Discussion}

The temperature, $\mathrm{pH}$, and salinity remained stable during the exposure period (monitored at the beginning and the end of the bioassay), temperature: $19.1 \pm 0.14{ }^{\circ} \mathrm{C} ; \mathrm{pH}$ : $7.70 \pm 0.01$; salinity: 35 . The dissolved oxygen decreased over time as no aeration was provided, but it remained above the limit of $5 \mathrm{mg} / \mathrm{L}(5.4 \pm 0.1)$. The average fish larvae survival in control, 0.1, 1, $10 \mathrm{mg}$ PE/L treatments was, respectively, 96.25\%, 98.44\%, 100.00\%, and $97.50 \%$; in treatments with live preys added; and $87.50 \%, 93.75 \%, 96.89 \%$, and 95.00\% in treatments with no feed added.

\subsection{Ingestion of Polyethylene Microplastics (PE-MPs) and Prey Items by Meagre Fish Larvae}

Larvae exposed to PE-MPs presented MPs particles in their gut. The number of PE-MPs in the larval gut was not dependent on the tested concentration $\left(\mathrm{F}_{(2,23)}=2.924\right.$, $p=0.074$, Table 1), but it was significantly lower in the presence of live prey $\left(\mathrm{F}_{(1,23)}=5.351\right.$, $p=0.030)$. Although, no interaction was observed between both factors $\left(\mathrm{F}_{(2,23)}=0.5364\right.$, $p=0.592)$.

The observed low numbers of PE-MPs in the larval fish gut (independent of PEMPs concentration) suggest unintentional intake followed by intentional elimination (or intentional spitting). Since meagre larvae possess a gut capacity to accumulate 8-15 Artemia prey of 500-800 $\mu \mathrm{m}$ in size (as observed in Figure 2-control conditions), they had the potential for accumulating at least a similar number of PE-MPs than prey, particularly under starvation (i.e., in treatments where no prey was provided for $7 \mathrm{~h}$ ). In addition, 
PE-MPs tested concentration were considerably higher (in the number of particles) than the total number of the prey supplied to fish larvae; thus, an unintentional capture and retention for "digestion" (i.e., without spitting) would result in a higher number of PE-MPs in larval gut. Yet, this was not the case with meagre larvae. In fact, some replicates (which consisted of a pool of three larvae) did not present any PE-MPs, or presented an average number $<1$ particle per larvae.

Table 1. Number of polyethylene microplastics (PE-MPs) ingested by Argyrosomus regius larvae, in the presence and absence of live prey (Artemia metanauplii). Data are presented as mean \pm standard error of the mean.

\begin{tabular}{ccc}
\hline [PE-MPs] $\mathbf{~ m g} / \mathbf{L}$ & without Food & with Food \\
\hline $\mathbf{0}$ & - & - \\
$\mathbf{0 . 1}$ & $1 \pm 0.2$ & $0.2 \pm 0.3$ \\
$\mathbf{1}$ & $1.2 \pm 0.1$ & $0.8 \pm 0.2$ \\
$\mathbf{1 0}$ & $1.3 \pm 0.4$ & $1.1 \pm 0.2$ \\
\hline
\end{tabular}

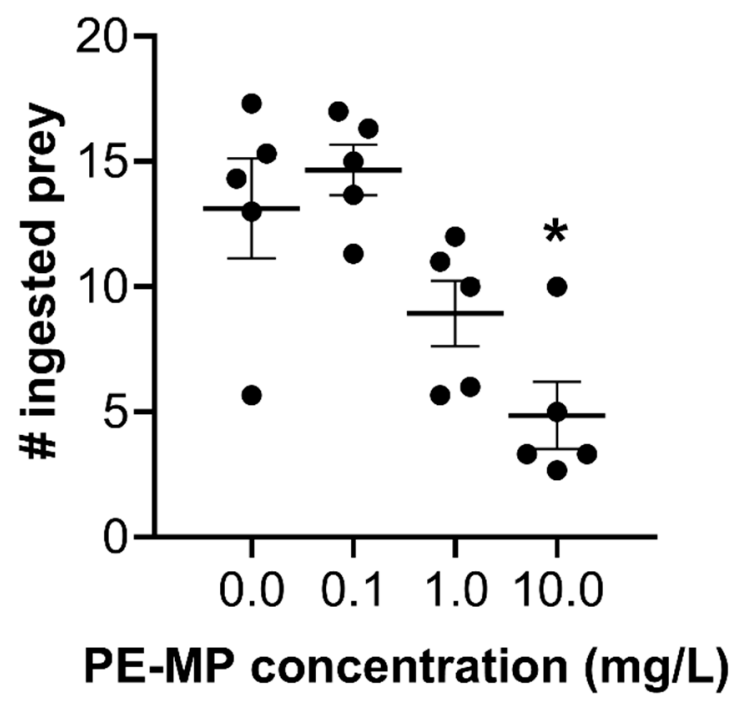

Figure 2. Number of Artemia nauplii (prey) ingested by Argyrosomus regius larvae exposed to polyethylene microplastics (PE-MPs) after $3 \mathrm{~h}$ feeding period. Data are presented as mean \pm standard error of the mean. $\left(^{*}\right)$ denote significant statistical differences compared to control condition, $0 \mathrm{mg}$ PE-MPs / L (Dunnet's post-hoc test, $p<0.05$ ).

Microplastics' ingestion was expected, as these particles can resemble planktonic organisms or particulate food items in size $(65-125 \mu \mathrm{m})$ and shape (irregular to bead shape); thus, becoming available to be captured by many planktivores such as fish larvae. Nevertheless, most fish larvae also use visual and chemical (odor, palatability) stimuli to detect suitable food or egest indigestible items [36]. Considering obtained results, meagre fish larvae seem to rely on chemical stimuli to recognize PE-MP as inedible materials and then spit them, after their active or passive ingestion. Such behavior was observed in zebrafish (Danio rerio), which seemed to ingest PE particles quickly, followed by egestion [37]. Low number of MPs particles was equally found in the European white fish larval gut (Coregonus lavaretus, dph not mentioned), which presented 0-6 particles of $90 \mu \mathrm{m}$ polystyrene beads per larvae (concentration tested up to 30 beads $/ \mathrm{mL}$ ) after 2-6 hexposure [38], and also in seabass fish larvae (Dicentrarchus labrax, 7-43 dph), which presented 1.4 to 3.3 particles of 10-45 $\mu \mathrm{m}$ PE microbeads per larval gut (concentration tested up to $12 \mathrm{mg} / \mathrm{L}$ ) [39]. Moreover, recent studies observed that the abundance of MPs inside fish larvae is related to feeding type, the ingestion of MPs being lower in carnivorous/planktivorous comparatively to omnivores and filter feeders $[40,41]$. 
The exposure to PE-MPs affected the number of prey ingested/digested by fish larvae, with a lower number of prey found in larvae exposed to the highest tested concentration compared to the control condition $\left(\mathrm{F}_{(3,16)}=9.161, p=0.001\right)$ (Figure 2).

Fed larvae did not reveal high(er) levels of PE-MPs in their gut that could have occupied gut volumetric space (Table 1). The low number of prey found in fish could be due to four potential reasons: (i) in the presence of MPs, fish larvae potentially spit more particles from their mouth to promote water flux through gills; thus, food items would also be excluded from their mouth; (ii) alteration of gut microbiota and/or irritability/damage of the gut tissues after ingestion/egestion of MPs (although the number of ingested PE-MP remains low after $7 \mathrm{~h}$, it is unclear how many particles they ingested/spit during that period); (iii) a decrease in larvae locomotion/swimming activity due to neurotoxicity or oxidative stress induced by PE-MP exposure/ingestion (as discussed below); and (vi) an increase in prey digestion processing induced by the ingestion/egestion of PE-MPs (less likely, as prey remained mostly undigested at the sampling time).

Although the numbers of ingested PE-MPs were generally low, with meagre fish revealing the potential capacity to egest (spit) the majority of them, the presence and ingestion of MPs may still represent a significant threat in aquaculture facilities where the range of sizes, shapes, and chemical compositions is wider. The effects are also likely to vary spatially, as MPs density relies on environmental variables (e.g., flow, volume capacity). In addition, most aquaculture facilities are typically located in littoral zones, where high densities of MPs have been reported as a result of photooxidation and mechanical degradation of macro- and microplastics, or a result of WWTP discharges [42,43].

\subsection{Effects of PE-MPs Exposure and Food Supply on the Biochemical Responses of Meagre Larvae}

The presence and ingestion of PE-MPs induced several biochemical responses on meagre fish larvae, as depicted in Figures $3-5$ and Table 2 (for statistical support). In our study, although the presence/absence of food altered the biochemical responses of organisms, in general, it seems not to change the effects of MPs since no interaction on the two-way ANOVA was observed to all endpoints evaluated but lipid peroxidation (LPO, Table 2).

Results show a generalized increment (up to 81 and 101\%, in the absence and presence of food, respectively) on glutathione levels (tGSH) of meagre larvae exposed at concentrations $\geq 1 \mathrm{mg}$ PE-MPs / L (Figure 3a, Table 2). Moreover, significant inhibition of catalase activity (up to $31 \%$ and $48 \%$ in the absence and presence of food, respectively) was observed in all tested concentrations in the presence of food and at 0.1 and $1 \mathrm{mg} P E-\mathrm{MP} / \mathrm{L}$ in the absence of food (Figure 3b, Table 2).

Such results are underlying the activation of the antioxidant system to deal with the generation of reactive oxygen species (ROS). ROS generation could be a result of, for instance, an immune response triggered after the ingestion of PE-MPs as a consequence of chemical stimuli or a potential mechanical damage/abrasion or proteolytic damage to the epithelial cells of the gut lumen of fish larvae. Activation of an immune response was also previously inferred by upregulated genes in zebrafish larvae (D. rerio) after exposure to polyethylene and polystyrene microplastics [44]. Although CAT is considered an enzyme of the first line of defense that directly eliminates ROS, its activity is regulated by other players in the antioxidant system, such as glutathione peroxidase, superoxide dismutase, and even total glutathione levels, and relies on the energy available for their activation [45]. In our case, CAT inhibition was (indeed) accompanied by an increment of $\mathrm{tGSH}$, which seemed to counteract the potential oxidative damage, as observed by the absence of an increase in lipid peroxidation (LPO, Figure 3c, Table 2). The triggering of glutathione system to prevent oxidative damage, namely de novo synthesis and recycling of reduced GSH [46], was also observed in other marine invertebrates such as rotifers (Brachionus koreanus) and crabs (Eriocheir sinensis) exposed to MPs (as reviewed in [47]). Glutathione has been highlighted as one of the key components of the antioxidant system in preventing oxidation of lipids and proteins by various environmental xenobiotics, including MPs [47-49]. 
a)

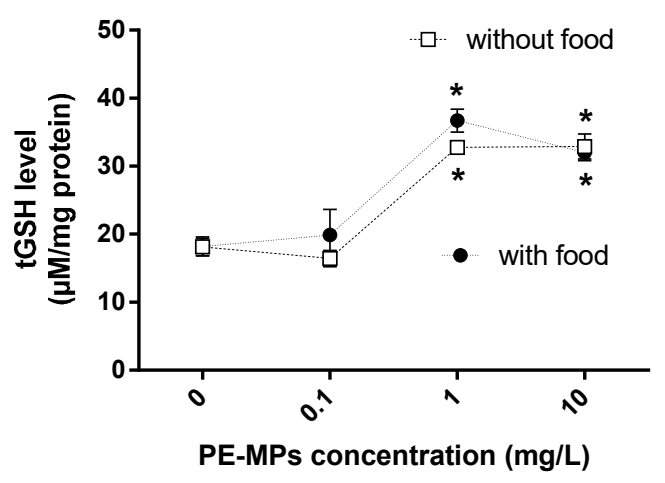

c)

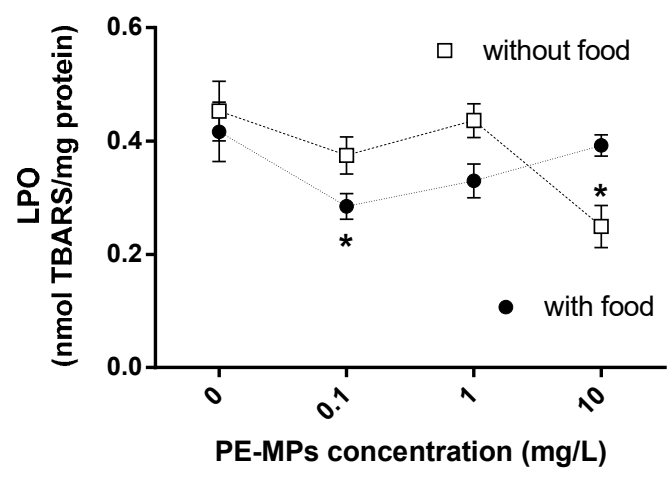

b)

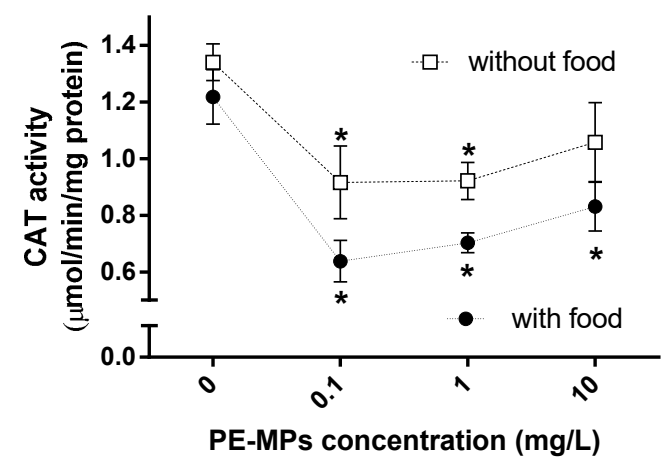

d)

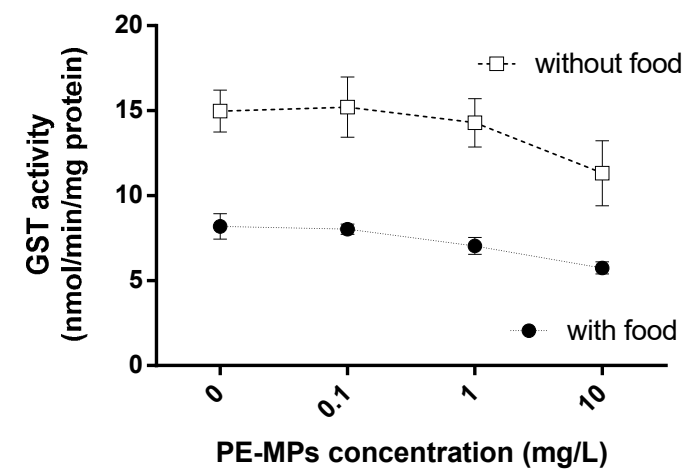

Figure 3. Biochemical responses of Argyrosomus regius larvae after $7 \mathrm{~h}$ exposure to polyethylene microplastics (PE-MPs), in the presence or absence of food, on (a) catalase activity (CAT), (b) total glutathione levels (tGSH), (c) glutathione-Stransferase activity (GST) and (d) Lipid peroxidation (LPO) in the presence (black circle) and absence (white square) of food. Data is presented as mean \pm standard error of the mean. $\left({ }^{*}\right)$ denote significant statistical differences compared to respective control, 0 mg PE-MPs/L (Dunnett's post-hoc test, $p<0.05)$.

Exposed meagre larvae also revealed an increase (up to 35\%) in the aerobic energy production, particularly at 1 and $10 \mathrm{mg} / \mathrm{L}$ PE-MPs for starved larvae, and at 0.1 and $1 \mathrm{mg} / \mathrm{L}$ of PE-MP on fed larvae (Figure 4). Such aerobic energy production could have been allocated to the generalized synthesis and recycling of GSH to combat ROS and oxidative damage. In fact, exposed larvae revealed a decrease in LPO levels, particularly under starvation, in the highest tested PE-MPs concentration (10 mg/L) (Figure 3c, Table 2). Such a decrease in LPO could be a result of the increase in tGSH levels, and a concomitant decrease in lipid reserves (although not measured, but expected to be mobilized under starvation/ingestion of PE-MPs by meagre fish larvae that also possesses a considerable fast growth) [50]. Fed fish larvae were able to obtain and replenish some of the lipid reserves, which could explain the relatively stable LPO in most of PE-MPs concentration (Figure 3c, Table 2).

Despite exposure to, and/or ingestion of, PE-MPs triggered responses from tGSH, it seems not to significantly alter GST activity (Figure 3d, Table 2), suggesting no alteration of this enzyme biotransformation action, which was already observed in Pomatoschistus microps exposed up to $185 \mu \mathrm{g} / \mathrm{L}$ microspheres $(1-5 \mu \mathrm{m})$ [51]. Nevertheless, meagre fish under starvation presented higher GST activity than larvae fed with Artemia microcrustaceans (Figure 3d, Table 2). These results are not surprising, since food deprivation is also a known stressor to fish with the potential to induce ROS generation and oxidative stress, which involves GST, as observed in the juveniles of Siberian sturgeon (Acipenses baerii) and European sea bass (Dicentrarchus labrax) after starvation periods [50,52]. 


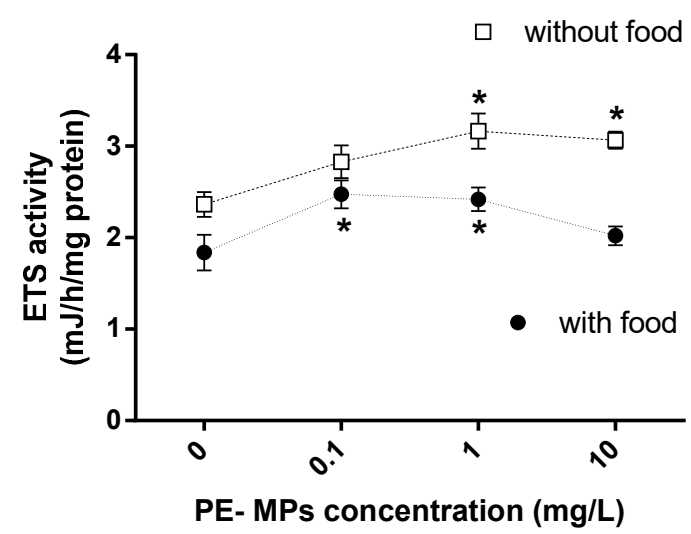

Figure 4. Responses of Argyrosomus regius larvae after $7 \mathrm{~h}$ exposure to polyethylene microplastics (PE-MPs) on electron transport system activity (ETS) in the presence (black circle) and absence (white square) of food. $\left({ }^{*}\right)$ denote significant statistical differences compared to respective control, $0 \mathrm{mg}$ PE-MPs/L (Dunnett's post-hoc test, $p<0.05$ ).

Table 2. Two-way ANOVA results testing for concentrations of polyethylene microplastics [PE-MPs], presence or absence of food ( $\mathrm{p} / \mathrm{a}$ food), and interaction between both on lipid peroxidation (LPO), catalase activity (CAT), glutathione-S-transferase activity (GST) total glutathione contents (tGSH), aerobic energy production (ETS-electron transport system) and cholinesterase activity (ChE).

\begin{tabular}{|c|c|c|c|c|}
\hline & & Sums of Squares & F-Value, $d f$ & $p$-Value \\
\hline \multirow{3}{*}{ LPO } & [PE-MPs] & 0.084 & $\mathrm{~F}_{(3,32)}=4.207$ & 0.013 \\
\hline & $\mathrm{p} / \mathrm{a}$ food & 0.005 & $\mathrm{~F}_{(1,32)}=0.7594$ & 0.390 \\
\hline & Interaction & 0.099 & $\mathrm{~F}_{(3,32)}=4.919$ & 0.006 \\
\hline \multirow{3}{*}{ CAT } & [PE-MPs] & 1.57 & $\mathrm{~F}_{(3,32)}=12.40$ & $<0.001$ \\
\hline & $\mathrm{p} / \mathrm{a}$ food & 0.45 & $\mathrm{~F}_{(1,32)}=10.61$ & 0.003 \\
\hline & Interaction & 0.03 & $F_{(3,32)}=0.2496$ & 0.861 \\
\hline \multirow{3}{*}{ GST } & [PE-MPs] & 62.81 & $\mathrm{~F}_{(3,32)}=2.952$ & 0.047 \\
\hline & $\mathrm{p} / \mathrm{a}$ food & 448.30 & $F_{(1,32)}=63.21$ & $<0.0001$ \\
\hline & Interaction & 4.524 & $F_{(3,32)}=0.2126$ & 0.887 \\
\hline \multirow{3}{*}{ tGSH } & [PE-MPs] & 2407 & $\mathrm{~F}_{(3,32)}=46.88$ & $<0.0001$ \\
\hline & $\mathrm{p} / \mathrm{a}$ food & 27.55 & $\mathrm{~F}_{(1,32)}=1.610$ & 0.214 \\
\hline & Interaction & 43.74 & $F_{(3,32)}=0.8519$ & 0.476 \\
\hline \multirow{3}{*}{ ETS } & [PE-MPs] & 2.68 & $\mathrm{~F}_{(3,32)}=7.756$ & 0.0005 \\
\hline & $\mathrm{p} / \mathrm{a}$ food & 4.47 & $F_{(1,32)}=38.76$ & $<0.0001$ \\
\hline & Interaction & 0.66 & $\mathrm{~F}_{(3,32)}=1.919$ & 0.146 \\
\hline \multirow{3}{*}{ ChE } & [PE-MPs] & 9037 & $F_{(3,32)}=25.16$ & $<0.0001$ \\
\hline & $\mathrm{p} / \mathrm{a}$ food & 862.5 & $\mathrm{~F}_{(1,32)}=7.204$ & 0.0114 \\
\hline & Interaction & 998.4 & $\mathrm{~F}_{(3,32)}=2.779$ & 0.0570 \\
\hline
\end{tabular}

Regarding cholinergic neurotransmission, the present results showed a decrease in the cholinesterase activity of $A$. regius larvae after only $7 \mathrm{~h}$ exposure to all tested PEMPs (even environmentally relevant [10]) in the presence and absence of food (Figure 5, Table 2). Cholinesterase has a vital role in the transmission of impulses between neurons by hydrolysing the acetylcholine into choline in synaptic clefts. The consequence of cholinesterase inhibition is the accumulation of neurotransmitters in the synaptic cleft and disturbance of nerve impulse transmission. The observed inhibition rate of ChE (up to $25 \%$ ) has been considered high enough to induce adverse effects in neurofunction in other exposed organisms, including fish [53], among which motor, sensory, or cognitive activities are highly affected. The mechanisms behind $\mathrm{ChE}$ inhibition remain unclear, but several hypotheses have been raised. For instance, exposure to MPs has the potential to increase reactive oxygen species proliferation and oxidative damage, which can inclusively affect 
the cells of the nervous system and, thus, neurotransmission [53]. The search for food, and the ingestion of indigestible particles such as MPs, seem to impose developmental costs to meagre fish larvae, by affecting energy assimilation and increasing energetic costs (for detoxification), which can ultimately lead to a decrease in organism activity and eventually neurotransmission $[54,55]$. ChE inhibition has also been theoretically related to plasticizers or unknown hazardous chemicals released by MPs and to non-cholinergic functions related to neurite growth, synaptogenesis, cell migration, proliferation, and cell apoptosis [53]. In our case, meagre fish larvae exposed to pristine PE-MPs revealed an increment in glutathione levels and increased energy consumption to reduce ROS and avoid oxidative damage. Thus, the inhibition of $\mathrm{ChE}$ is potentially related to such readjustments on antioxidant systems and aerobic metabolism that could have affected fish larvae behavior (i.e., decrease in swimming activity-although not measured) and reduce cholinergic transmission. $\mathrm{ChE}$ inhibition can also be related to non-cholinergic functions or other parallel toxic mechanisms, although these mechanisms remain to be determined in the presence of MPs. Regardless of the mechanisms behind neurotoxicity, ChE inhibition in fish would be alarming, taking into consideration the ubiquity of MPs in the aquatic environment and the pivotal role of this enzyme in neurological function, which is crucial to control several physiological (e.g., growth, reproduction) and behavioral (e.g., swimming) processes that directly or indirectly may influence individual and population fitness.

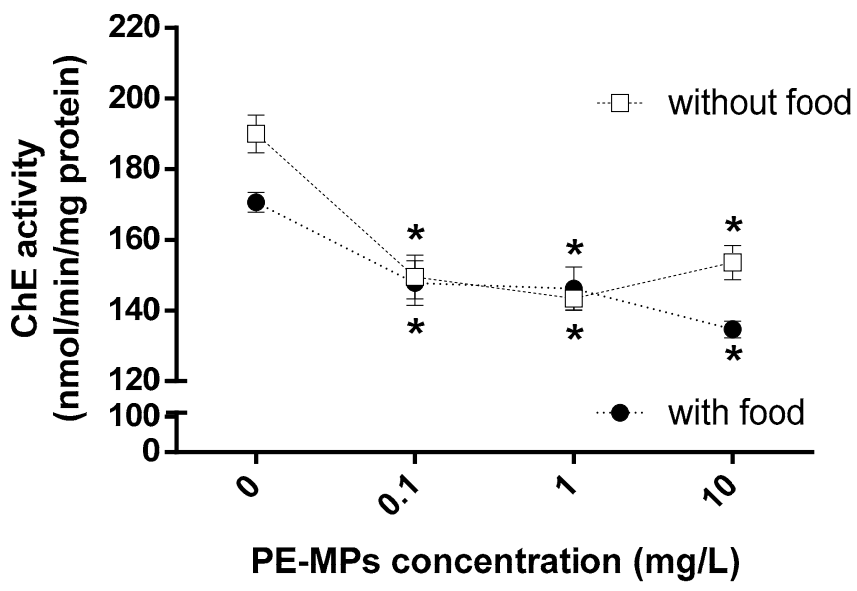

Figure 5. Responses of Argyrosomus regius larvae after $7 \mathrm{~h}$ exposure to polyethylene microplastics (PE-MPs) on Cholinesterase activity (ChE) in the presence (black circle) and absence (white square) of food. $\left({ }^{*}\right)$ denote significant statistical differences compared to respective control, $0 \mathrm{mg} \mathrm{PE}-\mathrm{MP} / \mathrm{L}$ (Dunnett's post-hoc test, $p<0.05)$.

\section{Concluding Remarks}

Our results provide the first evidence of the potential adverse effects of MPs on finfish hatcheries under realistic scenarios (i.e., presence and absence of food). Meagre fish larvae seems to be able to ingest and spit PE-MPs, however with metabolic requirements and energetic costs associated. The increment of non-enzymatic antioxidant defenses and aerobic energy production, in the present study, revealed that fish larvae were able to cope with the increase of ROS triggered by the ingestion and presence of MPs and prevent oxidative damage. On the other hand, farmed organisms are frequently experiencing feeding restrictions during several periods, namely, night period, to monitor water quality and prevent diseases. Consequently, and considering the presence of MPs in aquaculture systems, their toxic effects could be enhanced in the periods of absence of food.

In conclusion, our results showed that, although organisms had the ability to cope with stress (at short-term exposure to PE-MPs), the effects observed can compromise the success/efficiency of aquaculture production, because (i) MPs triggered biochemical responses on vulnerable early life stages - which can lead to an inefficient finfish growth and development at short-term and (ii) cumulative long-term effects that cannot be ruled out could 
threaten the organisms' health and life traits. Moreover, the effects of microplastics can differ due to the variety of polymeric composition, size, shape, and plasticizers/adsorbed contaminants. Thus, the presence of MPs and their vector nature should be deeply studied and understood in aquaculture scenarios, and mitigation strategies should be adopted to prevent such contaminations.

Author Contributions: Conceptualization and visualization: A.L.P.S., D.C., A.C.M.R., R.J.M.R., and R.M.; methodology: D.C. and A.C.M.R.; validation: A.L.P.S., D.C., A.C.M.R., R.J.M.R., R.M., and C.G.; formal analysis: A.L.P.S., D.C., A.C.M.R., R.J.M.R., R.M., and C.G.; resources: A.C.-M., S.C., F.S., P.P.-F., A.L.P.S., and R.J.M.R.; data curation: A.L.P.S., D.C., A.C.M.R., and C.G.; writing-original draft preparation: A.L.P.S., D.C., A.C.M.R., and C.G.; writing-review and editing: A.L.P.S., D.C., A.C.M.R., R.J.M.R., R.M., C.G., A.C.-M., S.C., F.S., P.P.-F., and A.M.V.M.S.; supervision: A.L.P.S., R.J.M.R., F.S., P.P.-F., and A.M.V.M.S.; project administration: A.L.P.S., R.J.M.R., A.M.V.M.S., F.S., and P.P.-F.; funding acquisition: A.L.P.S., R.J.M.R., A.M.V.M.S., and P.P.-F. All authors have read and agreed to the published version of the manuscript.

Funding: This research was funded through CESAM (UIDP/50017/2020+UIDB/50017/2020), with the financial support from FCT/MCTES through national funds; to the research project ComPET (PTDC/CTA-AMB/30361/2017) funded by FEDER, through COMPETE 2020_Programa Operacional Competitividade e Internacionalização (POCI), and by national funds (OE); to the research project Diversiaqua II (Mar2020-P02M01-0656P) supported by MAR2020 program; and to the Integrated Program of SR\&T D' Smart Valorisation of Endogenous Marine Biological Resources Under a Changing Climate' (reference Centro-01-0145-FEDER-000018), co-funded by Centro (2020) program, Portugal 2020, European Union, through the European Regional Development Fund. A.L.P.S. and R.M. were supported by CEECIND/01366/2018 and CEECIND/01329/2017, respectively. D.C. has a research contract within the project ComPET (nr. 5662).

Institutional Review Board Statement: The current research was led by accredited Researchers by the Portuguese National Authority for Animal Health (DGAV-Direção Geral de Alimentação e Veterinária) for the practice of animal experimentation (FELASA Category B), following the Portuguese Law nr. 113/2013 and the European Directive 2010/63/EU of the European Parliament and the European Union Council on the protection of animals used for scientific purposes.

Informed Consent Statement: Not applicable.

Data Availability Statement: The data presented in this study is available in the current manuscript, raw data is available on request from the corresponding author.

Acknowledgments: We would like to thank to Sara Silva, Lígia Santana, and Joana Figueiredo for the valuable help when handling the fish larvae for testing.

Conflicts of Interest: The authors declare no conflict of interest.

\section{References}

1. FAO. The State of World Fisheries and Aquaculture; FAO: Rome, Italy, 2018.

2. Hamre, K.; Yúfera, M.; Rønnestad, I.; Boglione, C.; Conceição, L.E.C.; Izquierdo, M. Fish larval nutrition and feed formulation: Knowledge gaps and bottlenecks for advances in larval rearing. Rev. Aquac. 2013, 5, S26-S58. [CrossRef]

3. China, V.; Holzman, R. Hydrodynamic starvation in first-feeding larval fishes. Proc. Natl. Acad. Sci. USA 2014, 111, 8083-8088. [CrossRef] [PubMed]

4. Campoverde, C.; Rodriguez, C.; Perez, J.; Gisbert, E.; Estevez, A. Early weaning in meagreArgyrosomus regius: Effects on growth, survival, digestion and skeletal deformities. Aquac. Res. 2017, 48, 5289-5299. [CrossRef]

5. Wang, W.; Gao, H.; Jin, S.; Li, R.; Na, G. The ecotoxicological effects of microplastics on aquatic food web, from primary producer to human: A review. Ecotoxicol. Environ. Saf. 2019, 173, 110-117. [CrossRef] [PubMed]

6. Wang, W.; Ge, J.; Yu, X.-Y. Bioavailability and toxicity of microplastics to fish species: A review. Ecotoxicol. Environ. Saf. 2020, 189, 109913. [CrossRef] [PubMed]

7. Lusher, A.; Hollman, P.; Mendozal, J. Microplastics in Fisheries and Aquaculture: Status of Knowledge on Their Occurrence and Implications for Aquatic Organisms and Food Safety; FAO Fisheries and Aquaculture Technical Paper 615; FAO: Rome, Italy, 2017; p. 147.

8. Ma, J.; Niu, X.; Zhang, D.; Lu, L.; Ye, X.; Deng, W.; Li, Y.; Lin, Z. High levels of microplastic pollution in aquaculture water of fish ponds in the Pearl River Estuary of Guangzhou, China. Sci. Total Environ. 2020, 744, 140679. [CrossRef] [PubMed]

9. Chen, M.; Jin, M.; Tao, P.; Wang, Z.; Xie, W.; Yu, X.; Wang, K. Assessment of microplastics derived from mariculture in Xiangshan Bay, China. Environ. Pollut. 2018, 242, 1146-1156. [CrossRef] 
10. Conkle, J.L.; Del Valle, C.D.B.; Turner, J.W. Are We Underestimating Microplastic Contamination in Aquatic Environments? Environ. Manag. 2018, 61, 1-8. [CrossRef]

11. Pabortsava, K.; Lampitt, R.S. High concentrations of plastic hidden beneath the surface of the Atlantic Ocean. Nat. Commun. 2020, 11, 1-11. [CrossRef]

12. Dong, H.; Chen, Y.; Wang, J.; Zhang, Y.; Zhang, P.; Li, X.; Zou, J.; Zhou, A. Interactions of microplastics and antibiotic resistance genes and their effects on the aquaculture environments. J. Hazard. Mater. 2021, 403, 123961. [CrossRef]

13. Hanachi, P.; Karbalaei, S.; Walker, T.R.; Cole, M.; Hosseini, S.V. Abundance and properties of microplastics found in commercial fish meal and cultured common carp (Cyprinus carpio). Environ. Sci. Pollut. Res. 2019, 26, 23777-23787. [CrossRef] [PubMed]

14. Solovyev, M.M.; Campoverde, C.; Öztürk, S.; Moreira, C.; Diaz, M.; Moyano, F.J.; Estévez, A.; Gisbert, E. Morphological and functional description of the development of the digestive system in meagre (Argyrosomus regius): An integrative approach. Aquaculture 2016, 464, 381-391. [CrossRef]

15. Wang, F.; Wang, B.; Duan, L.; Zhang, Y.; Zhou, Y.; Sui, Q.; Xu, D.; Qu, H.; Yu, G. Occurrence and distribution of microplastics in domestic, industrial, agricultural and aquacultural wastewater sources: A case study in Changzhou, China. Water Res. 2020, 182, 115956. [CrossRef] [PubMed]

16. Roo, J.; Hernandez-Cruz, C.M.; Borrero, C.; Schuchardt, D.; Fernández-Palacios, H. Effect of larval density and feeding sequence on meagre (Argyrosomus regius; Asso, 1801) larval rearing. Aquaculture 2010, 302, 82-88. [CrossRef]

17. Silva, C.J.; Silva, A.L.P.; Gravato, C.; Pestana, J.L. Ingestion of small-sized and irregularly shaped polyethylene microplastics affect Chironomus riparius life-history traits. Sci. Total Environ. 2019, 672, 862-868. [CrossRef]

18. Prata, J.C.; Reis, V.; Matos, J.T.; Da Costa, J.P.; Duarte, A.C.; Rocha-Santos, T. A new approach for routine quantification of microplastics using Nile Red and automated software (MP-VAT). Sci. Total Environ. 2019, 690, 1277-1283. [CrossRef]

19. Rocha, R.J.M.; Ribeiro, L.; Costa, R.; Dinis, M.T. Does the presence of microalgae influence fish larvae prey capture? Aquac. Res. 2008, 39, 362-369. [CrossRef]

20. Abe, F.R.; Soares, A.M.V.M.; De Oliveira, D.P.; Gravato, C. Toxicity of dyes to zebrafish at the biochemical level: Cellular energy allocation and neurotoxicity. Environ. Pollut. 2018, 235, 255-262. [CrossRef]

21. Campos, D.; Gravato, C.; Quintaneiro, C.; Soares, A.M.; Pestana, J.L.T. Responses of the aquatic midge Chironomus riparius to DEET exposure. Aquat. Toxicol. 2016, 172, 80-85. [CrossRef]

22. Meireles, G.; Daam, M.A.; Sanches, A.L.M.; Zanoni, M.V.B.; Soares, A.M.; Gravato, C.; De Oliveira, D.P. Red disperse dyes (DR 60, DR 73 and DR 78) at environmentally realistic concentrations impact biochemical profile of early life stages of zebrafish (Danio rerio). Chem. Interact. 2018, 292, 94-100. [CrossRef]

23. Rodrigues, A.D.C.; Gravato, C.; Quintaneiro, C.; Golovko, O.; Žlábek, V.; Barata, C.; Soares, A.M.; Pestana, J.L.T. Life history and biochemical effects of chlorantraniliprole on Chironomus riparius. Sci. Total Environ. 2015, 508, 506-513. [CrossRef]

24. Bird, R.; Draper, H. [35] Comparative studies on different methods of malonaldehyde determination. Methods Enzymol. 1984, 105, 299-305. [CrossRef] [PubMed]

25. Ohkawa, H.; Ohishi, N.; Yagi, K. Assay for lipid peroxides in animal tissues by thiobarbituric acid reaction. Anal. Biochem. 1979, 95, 351-358. [CrossRef]

26. Clairborne, A. Catalase activity. In Handbook of Methods for Oxygen Radical Research; Greenwald, R.A.E., Ed.; CRC Press: Boca Raton, FL, USA, 1985; pp. 283-284.

27. Habig, W.H.; Pabst, M.J.; Jakoby, W.B. Glutathione S-transferases. The first enzymatic step in mercapturic acid formation. J. Biol. Chem. 1974, 249, 7130-7139. [PubMed]

28. Ellman, G.L.; Courtney, K.; Andres, V.; Featherstone, R.M. A new and rapid colorimetric determination of acetylcholinesterase activity. Biochem. Pharmacol. 1961, 7, 88-95. [CrossRef]

29. Guilhermino, L.; Lopes, M.C.; Carvalho, A.P.; Soares, A.M.V.M. Acetylcholinesterase Activity in Juveniles of Daphnia magna Straus. Bull. Environ. Contam. Toxicol. 1996, 57, 979-985. [CrossRef]

30. Domingues, I.; Gravato, C. Oxidative Stress Assessment in Zebrafish Larvae. In Advanced Structural Safety Studies; Springer Science and Business Media LLC: Berlin/Heidelberg, Germany, 2018; Volume 1797, pp. 477-486.

31. Baker, M.A.; Cerniglia, G.J.; Zaman, A. Microtiter plate assay for the measurement of glutathione and glutathione disulfide in large numbers of biological samples. Anal. Biochem. 1990, 190, 360-365. [CrossRef]

32. Campos, D.; Gravato, C.; Fedorova, G.; Burkina, V.; Soares, A.M.V.M.; Pestana, J.L.T. Ecotoxicity of two organic UV-filters to the freshwater caddisfly Sericostoma vittatum. Environ. Pollut. 2017, 228, 370-377. [CrossRef]

33. Rodrigues, A.D.C.; Gravato, C.; Silva, C.J.; Pires, S.F.S.; Costa, A.P.L.; Conceição, L.E.; Santos, P.; Costas, B.; Calheiros, J.; Castro-Cunha, M.; et al. Seasonal Temperature Fluctuations Differently Affect the Immune and Biochemical Parameters of Diploid and Triploid Oncorhynchus mykiss Cage-Cultured in Temperate Latitudes. Sustainability 2020, 12, 8785. [CrossRef]

34. De Coen, W.M.; Janssen, C.R. The use of biomarkers in Daphnia magna toxicity testing. IV. Cellular Energy Allocation: A new methodology to assess the energy budget of toxicant-stressed Daphnia populations. J. Aquat. Ecosyst. Stress Recover. 1997, 6, 43-55. [CrossRef]

35. Bradford, M.M. A rapid and sensitive method for the quantitation of microgram quantities of protein utilizing the principle of protein-Dye binding. Anal. Biochem. 1976, 72, 248-254. [CrossRef]

36. Rønnestad, I.; Yúfera, M.; Ueberschär, B.; Ribeiro, L.; Saele, Ø.; Boglione, C. Feeding behaviour and digestive physiology in larval fish: Current knowledge, and gaps and bottlenecks in research. Rev. Aquac. 2013, 5, S59-S98. [CrossRef] 
37. Kim, S.W.; Chae, Y.; Kim, D.; An, Y.-J. Zebrafish can recognize microplastics as inedible materials: Quantitative evidence of ingestion behavior. Sci. Total Environ. 2019, 649, 156-162. [CrossRef] [PubMed]

38. Huuskonen, H.; Folguera, J.S.; Kortet, R.; Akkanen, J.; Vainikka, A.; Janhunen, M.; Kekäläinen, J. Do whitefish (Coregonus lavaretus) larvae show adaptive variation in the avoidance of microplastic ingestion? Environ. Pollut. 2020, 262, 114353. [CrossRef]

39. Mazurais, D.; Ernande, B.; Quazuguel, P.; Severe, A.; Huelvan, C.; Madec, L.; Mouchel, O.; Soudant, P.; Robbens, J.; Huvet, A.; et al. Evaluation of the impact of polyethylene microbeads ingestion in European sea bass (Dicentrarchus labrax) larvae. Mar. Environ. Res. 2015, 112, 78-85. [CrossRef] [PubMed]

40. Mizraji, R.; Ahrendt, C.; Perez-Venegas, D.; Vargas, J.; Pulgar, J.; Aldana, M.; Ojeda, F.P.; Duarte, C.; Galbán-Malagón, C.J. Is the feeding type related with the content of microplastics in intertidal fish gut? Mar. Pollut. Bull. 2017, 116, 498-500. [CrossRef]

41. Zhang, C.; Wang, J.; Zhou, A.; Ye, Q.; Feng, Y.; Wang, Z.; Wang, S.; Xu, G.; Zou, J. Species-specific effect of microplastics on fish embryos and observation of toxicity kinetics in larvae. J. Hazard. Mater. 2021, 403, 123948. [CrossRef]

42. Browne, M.A.; Crump, P.; Niven, S.J.; Teuten, E.; Tonkin, A.; Galloway, T.; Thompson, R. Accumulation of Microplastic on Shorelines Woldwide: Sources and Sinks. Environ. Sci. Technol. 2011, 45, 9175-9179. [CrossRef]

43. Cole, M.; Lindeque, P.; Halsband, C.; Galloway, T.S. Microplastics as contaminants in the marine environment: A review. Mar. Pollut. Bull. 2011, 62, 2588-2597. [CrossRef]

44. Limonta, G.; Mancia, A.; Benkhalqui, A.; Bertolucci, C.; Abelli, L.; Fossi, M.C.; Panti, C. Microplastics induce transcriptional changes, immune response and behavioral alterations in adult zebrafish. Sci. Rep. 2019, 9, 1-11. [CrossRef]

45. Regoli, F.; Giuliani, M.E. Oxidative pathways of chemical toxicity and oxidative stress biomarkers in marine organisms. Mar. Environ. Res. 2014, 93, 106-117. [CrossRef] [PubMed]

46. Dickinson, D.A.; Forman, H.J. Cellular glutathione and thiols metabolism. Biochem. Pharmacol. 2002, 64, 1019-1026. [CrossRef]

47. Prokić, M.D.; Radovanović, T.B.; Gavrić, J.P.; Faggio, C. Ecotoxicological effects of microplastics: Examination of biomarkers, current state and future perspectives. TrAC Trends Anal. Chem. 2019, 111, 37-46. [CrossRef]

48. Sen, C.K. Nutritional biochemistry of cellular glutathione. J. Nutr. Biochem. 1997, 8, 660-672. [CrossRef]

49. Lushchak, V.I. Glutathione Homeostasis and Functions: Potential Targets for Medical Interventions. J. Amino Acids 2012, 2012, 1-26. [CrossRef] [PubMed]

50. Babaei, S.; Kenari, A.A.; Hedayati, M.; Sadati, M.A.Y.; Metón, I. Effect of diet composition on growth performance, hepatic metabolism and antioxidant activities in Siberian sturgeon (Acipenser baerii, Brandt, 1869) submitted to starvation and refeeding. Fish Physiol. Biochem. 2016, 42, 1509-1520. [CrossRef]

51. Oliveira, M.C.L.; Ribeiro, A.L.P.; Hylland, K.; Guilhermino, L. Single and combined effects of microplastics and pyrene on juveniles (0+ group) of the common goby Pomatoschistus microps (Teleostei, Gobiidae). Ecol. Indic. 2013, 34, 641-647. [CrossRef]

52. Antonopoulou, E.; Kentepozidou, E.; Feidantsis, K.; Roufidou, C.; Despoti, S.; Chatzifotis, S. Starvation and re-feeding affect Hsp expression, MAPK activation and antioxidant enzymes activity of European Sea Bass (Dicentrarchus labrax). Comp. Biochem. Physiol. Part A Mol. Integr. Physiol. 2013, 165, 79-88. [CrossRef]

53. Prüst, M.; Meijer, J.; Westerink, R.H.S. The plastic brain: Neurotoxicity of micro- and nanoplastics. Part. Fibre Toxicol. 2020, 17, 1-16. [CrossRef]

54. Sokolova, I.M.; Frederich, M.; Bagwe, R.; Lannig, G.; Sukhotin, A.A. Energy homeostasis as an integrative tool for assessing limits of environmental stress tolerance in aquatic invertebrates. Mar. Environ. Res. 2012, 79, 1-15. [CrossRef]

55. Chen, Q.; Gundlach, M.; Yang, S.; Jiang, J.; Velki, M.; Yin, D.; Hollert, H. Quantitative investigation of the mechanisms of microplastics and nanoplastics toward zebrafish larvae locomotor activity. Sci. Total Environ. 2017, 1022-1031. [CrossRef] [PubMed] 